\title{
Assessment of Explicit and Implicit Self Esteem among Students of Different Social Categories
}

\author{
Shraddhesh Kumar Tiwari ${ }^{1 *}$, Ashok Kumar Patel $^{2}$, Dhananjay Kumar ${ }^{3}$
}

\section{ABSTRACT}

The evaluation of oneself is known as self esteem (James 1890). A healthy self esteem is necessary for mental well being and positive self concept. Low self esteem is cause to prejudice and assumed that people lack with self esteem would be most prejudiced against others (Stephan and Rrosenfeild 1978). The present study is aimed to assess the self esteem (explicit and implicit) among students of different social categories. Total 300 participants (100 general, 100 OBC and 100 SC / SC) selected from UG/PG enrolled students of DDU Gorakhpur University and affiliated colleges. Findings of the study reveal that explicit self esteem was high in general category members and implicit self esteem was found higher in other backward category but marginal difference from general category and SC/ST category.

Keywords: Explicit self esteem, implicit self esteem, Social categories.

Self esteem has been one of the most durable topics in broader domain of self research. Self esteem has strong interest and each new generation has brought a new set of findings to contribute. Individual differences in self esteem have a long, prelisted history in psychology. People differ reliably and consistently in their level of self esteem. The best way to characterize the differences between peoples is high versus low self esteem. In another ways, the concept of self esteem is viewed as conscious and unconscious process (Dijksterhuis and Bargh 2001, Fazio 1990). The implicit and explicit self esteem serve as similar function.

Explicit self-esteem refers to feelings of self-worth or the global evaluation of the self (Bosson \& Swann, 2009). There are three critics arise for explicit self esteem: First, the verbal questionnaires designed to assess explicit self-esteem may fail to capture self-views of which people are unaware (e.g., Greenwald \& Farnham, 2000). Second, even if people are aware of a given self-view, they might fail to express it due to self-presentational pressures that tempt them

\footnotetext{
${ }^{1}$ Ph. D in Psychology, D. D. U. Gorakhpur University

${ }^{2}$ Clinical Psychologist, Department of Neurology AIIMS, Ansari Nagar, New Delhi

${ }^{3}$ Associate Professor, Dept of Psychology D.D.U. Gorakhpur University

*Responding Author

(c) 2016 I S Tiwari, A Patel, D Kumar; licensee IJIP. This is an Open Access Research distributed under the terms of the Creative Commons Attribution License (http://creativecommons.org/licenses/by/2.0), which permits unrestricted use, distribution, and reproduction in any Medium, provided the original work is properly cited.
} 
to inflate their self-evaluations (Paulhus, 1991, 2002). Third, perhaps due to the previous limitations, researchers have failed to uncover strong and consistent support for the predictive validity of measures of explicit self-esteem (see Baumeister, Campbell, Krueger, \& Vohs), it is certainly possible that measures of explicit self-esteem may fail to capture important aspects of self-knowledge. With this possibility in mind, researchers developed several measures of implicit self-esteem (Boson, Swann \& Pennebaker, 2000). The most popular of these measures have been a pair namely the Implicit Association Test (IAT) and the Name-Letter Test (NLT). Both measures are based on the assumption that implicit self esteem is a valence association that a person has toward himself or herself. Although researchers differ in how they characterize this association, some consensus has emerged regarding its natured properties. This consensus and the research it has generated provide the basis for our assessment of the construct validity of measures of implicit self-esteem.

Implicit self esteem defined as "the introspectively unidentified or inaccurately identified" effect of self attitude on evaluation of self associated and self disassociated objects (Greenwald and Banaji 1995). It is recognized as automatic or unconscious process which plays a major role in almost all social psychological process (Bargh, 1984, Bargh and Chartrand 1999, Devine 1989, Bargh 2001, Fazio 1990). The scientific investigation of self esteem has no exception. Self esteem used to be seen as the result of conscious self evaluation process, but much recent work has emphasized the role of unconscious or implicit self evaluation process.

People like people more when they are members of same groups or social category (Tajfel 1970). Greenwald and Banaji (1995) provide a second source of evidence supporting the presence of automatic evaluation of self related objects. Research on Name Letter, mere ownership, and endowment effects indicate that people evaluate stimuli or objects associated with the self more positively than comparable objects not associated with self. This effect demonstrated for letter's in people's name (Hoorens \& Nuttin, 1993; Nuttin 1987) numbers in their birthday (Kitayama and Karasawa 1997), computer icons associated with the self (Feys, 1991), and a variety of physical objects that belong to self (Beggan, 1992; Belk, 1988; Kahneman, Knetsch, and Thaler 1990).

Research on relation between culture and self concept suggest that members of Eastern and Western cultures understand and evaluate to self quite differently (Fiske, Kitayama, Markus, \& Nibett, 1998; Markus \& Kitayama 1991); Triandis, 1989, 1995). Western cultures encourage individualistic approaches to self. Whereas, members of Western cultures are encourage to create and affirm positive individual identities. Eastern cultures predispose people to focus and obtain validation from their social rather than their individual identities. These differences in understanding and construction of self have important implication for implicit self regard. Hett, Sakuma \& Pelham (1999) examine the implicit and explicit self evaluation of a group of Japanese university students. They found that participants who had never lived in Western culture possessed lower implicit self regard and higher implicit group regard than did 
participants who had spent substantial time overseas. Pelham \& Hett (1999b) found that members of Eastern cultures possess highly favorable associations about the self. Specifically, the higher level of implicit group regard observed among participants with greater degree with exposure to Eastern cultures suggest that the need for positive regard (Pelham \& Hett, 1999 b) may be common to be both Eastern and Western cultures

An important impact on people's implicit self evaluation is ethnicity. Studies have shown that color of Euro-American people face higher level of prejudice and discrimination. They have been disparate treatment by criminal justice system, endure systematic economic disadvantages, and enjoy less social and professional prestige (Bradock \& Mcportland, 1987; Crosby, Bromely, \& Saxe, 1980; Sidanious and Pratto, 1999). A great deal of research has indicated that people of color are able to marshal a number of strategies in defense of favorable self conceptions. In fact, many studies have revealed that the self esteem of people of color is at least as high as, if not higher than, that of Euro- Americans (Crocker and Major, 1989; Cross, 1985; Porter \& Washington, 1979, 1989, 1993; Rosenberg, 1979).

Research has found that members of stigmatized or low status groups some time display subtle effect of their poor treatment by others. People of color can successfully deploy a number of strategies to protect their explicit self evaluation (Crocker and Major, 1989), their implicit self evaluation, especially their implicit group regard (the target of stereotypes), may still reflect the adverse effect of socially shared stereotypes (Hett and Pelham 1999). Members of many stigmatized groups (women, people of colors) often report that, whereas, their fellow in group members is frequently the target of discrimination, they themselves rarely feel the brunt of discrimination (Ruggiero \& Taylor, 1995; Taylor, Wright, Moghaddam, \& Lalonde, 1990; Taylor, Wright, \& Porter 1994). Stigmatize group members often develops high self esteem but findings also suggest that straightforward or consistently. The Specific objective of the study was to assess the explicit and implicit self esteem among students of different social categories. General objectives were (1) To compare the self esteem (explicit and implicit self esteem) among students of three social categories, (2) To investigate the effect of social category on explicit self esteem, (3) To explore the effect of social category on implicit self esteem.

\section{METHOD}

\section{Sample:}

Total 300 male subjects (100 from General category, 100 from Other Backward Categories, and 100 from Scheduled Caste / Scheduled Tribe Categories) were carried. Participants were enrolled in undergraduate and post graduate courses of Gorakhpur University and its affiliated colleges. The age range was 17 to 23 year. Mean age of total participants was found to be 19.77 year.

\section{Measures:}

(1) Explicit self esteem:

It was measured by Cooper Smith self esteem inventory (1982). This tool was developed to measure the evaluative attitude towards the self in social, academic, family and personal area of 
experiences. The main focus of this inventory was that, self esteem is significantly associated with personal satisfaction and affective functioning. The inventory consists 25 items in English language. Reliability coefficient of English version tool was ranging from .71 to .80. Present investigator adopts this tool in Hindi language. Reliability co-efficient of General category was (.87), other Backward Category (.79), and Scheduled Caste /Scheduled Tribe category (.74). The overall test-retest reliability coefficient was found to be $.80(\mathrm{p}<.01)$.

\section{(2)Implicit self esteem:}

It was discovered by Josef Nutty Jr. (1985). Name letter preferences are valid indicators of implicit self esteem and social cognition. The main signatures of implicit self-esteem are that, it should be a positive bias toward self associated stimuli. The name letter effect qualifies as a form of implicit self-esteem. It can be established as (a) name letters are associated with self (b) name letter evaluations are generally positively biased; (c) people are unaware of being biased toward their own name letters and (d) positive bias for name letters cannot easily be accounted for by factors other than the association between name letters and self.

To assess implicit self esteem, subjects were asked to provide personal information such as Name, Surname, education and other important information. After that, all subjects were asked to respond on explicit self esteem measured. In the mean time, present researcher jumbled alphabets of the Name and Surname randomly. Then, jumbled list of alphabets of Name and Surname were presented before subjects and instructed of aesthetic judgment of all alphabets of Name and Surname on a nine point scale ranging not beautiful to extremely beautiful. The sum of the ratings on alphabets made by subjects was divided the total number of the alphabet of Name and Surname to get the score. The scoring of Name and Surname made separately. The score of name and surname constitute the total score of implicit self esteem. Thus, in the Name Letter Task scoring were made separately for Name and surname and total score of Implicit self esteem.

\section{Procedure of Research:}

Participants were contacted in a group and request them to participate. Participants were not availability in particular place. Some are in university departments, lodge, hostels and their home. Group data collection was completed in university psychology department lab, seminar hall, and college's conference hall. After taking their consent and establishment of rapport, subjects were asked to provide personal information such as Name, Surname, education and other important information. After that, all subjects were asked to respond on explicit self esteem measured. In the mean time, present researcher jumbled alphabets of the Name and Surname randomly. Then, jumbled list of alphabets of Name and Surname were presented before subjects and instructed of aesthetic judgment of all alphabets of Name and Surname on a nine point scale ranging not beautiful to extremely beautiful. The sum of the ratings on alphabets made by subjects was divided the total number of the alphabet of Name and Surname to get the score. The scoring of Name and Surname made separately. The score of name and surname constitute the 
total score of implicit self esteem. Thus, in the Name Letter Task scoring were made separately for Name and surname and total score of Implicit self esteem.

\section{RESULTS:}

Table-1 shows the impact of social category on explicit self esteem, The main effect of social category was found significant $[\mathrm{F}(1,297)=9.06, \mathrm{p}<.01]$ on explicit self esteem and the respective means clearly shows that in comparison to OBC and SC/ST category members of General category have shown high explicit self esteem.

Table-1 Mean and F ratio of Explicit Self esteem

\begin{tabular}{|l|l|l|l|l|l|l|}
\hline Source & Mean & S.D. & Source & df & M.S & F \\
\hline General & 66.12 & 12.92 & Between & 2 & 15.75 & \\
SC/ST & 58.28 & 12.93 & Within & 297 & 173.76 & $9.06^{* *}$ \\
& 61.12 & 13.68 & Total & 299 & & \\
\hline
\end{tabular}

Note: $* *(\mathrm{p}<.01), *(\mathrm{p}<.05)$

As it has been stated earlier implicit self esteem was also measured in all social categories and a main effect of category found significant for implicit self esteem [F= (1, 297)7.87 $\mathrm{p}<.01]$, however there was marginal difference between the mean value of all three social categories (Table-2).

Table- 2: Mean and F ratio of implicit self esteem

\begin{tabular}{|l|l|l|l|l|l|l|}
\hline Category & Mean & S.D. & Source & df & MS & F \\
\hline General & 11.55 & 1.75 & Between & 2 & 32.03 & \\
OBC & 11.68 & 1.87 & Within & 297 & 4.06 & \\
SC/ST & 10.64 & 2.36 & Total & 299 & & \\
\hline
\end{tabular}

Note. $* *(\mathrm{p}<.01)$,

Implicit self esteem has two dimensions. Since, to measure implicit self esteem, the Name Letter Task has been utilized, it has a score for the letters of name and a different set of score for the letters of surname. To assess the impact of category, a one way ANOVA was conducted for these two dimension of Name Letter Task. The main effect of category has not been found significant $[F=(2,297) 2.19 \mathrm{p}>.05]$ for name but, the category effect of surname has been found significant $[F=(2,297) 8.21 \mathrm{p}<.01]$, again the mean of members of SC/ST category are lowest among the three social category and members of OBC category have reported highest implicit self esteem on both dimensions of Name Letter Task. The magnitude of the F ratio is greater for the scores 
of surname of Name Letter Task in comparison to scores of first name. Thus, the dimension of surname of Name Letter Task is more important in the constitution of implicit self esteem.

Table-3: Mean and F ratio of implicit self esteem (Name and Surname)

\begin{tabular}{|l|l|l|l|l|l|l|l|}
\hline Variables & Category & Mean & SD & Source & df & MS & F \\
\hline $\begin{array}{l}\text { Implicit Self- } \\
\begin{array}{l}\text { Esteem } \\
\text { (Name) }\end{array}\end{array}$ & General & 5.87 & 1.0 & Between & 2 & & \\
& OBC & 5.91 & 1 & Within & 297 & 2.16 & 2.18 \\
\hline $\begin{array}{l}\text { Implicit Self- } \\
\text { (Surname })\end{array}$ & General & 5.64 & .97 & Total & 299 & .98 & \\
& OBC & 5.77 & 1.27 & Within & 297 & 2.01 & $8.21^{* *}$ \\
& SC/ST & 5.03 & 1.73 & Total & 299 & & \\
\hline
\end{tabular}

Note $* *(\mathrm{p}<.01), *(\mathrm{p}<.05)$

\section{DISCUSSION:}

The objective of the study was to assess the explicit and implicit self esteem among students of different social categories. Self esteem is a personal opinion of one self and it is shaped by individual's relationship with others, experience and accomplishment in life. A healthy self esteem is necessary for mental well being and positive self concept (Mayo Clinic 2009). Having high self esteem means, an individual like himself or herself and this positive evaluation is based on specific experience.

It is noted that that explicit self esteem is highest in members of General category in comparison to Scheduled Caste/Scheduled Tribe category members Implicit self esteem suggest that implicit self esteem is highest in OBC in comparison to SC/ST category and General category students.

Implicit self esteem is result of automatic self evaluation process and it reflects unconscious association with the self (Greenwald and Banaji 1995). People with high implicit self esteem exhibit positively towards themselves and object associated with themselves in comparison to low implicit self esteem. Implicit self esteem Surname represent to collective self esteem and implicit self esteem Name suggest to individual implicit self esteem. Findings of results confirm that other backward category has high implicit self esteem in comparison to General category and SC/ST category. Fiske et al (1998) suggest that eastern and western culture understand and evaluate to self quite differentially. Peoples of eastern cultures focus to their social identity, rather than individual identities (Triandis, 1989, 95). These differences (eastern and western cultures) provide understanding and construction of self. According to this, SC/ST category has lowest implicit self esteem Surname. It indicates to lower social identity and construction of self. Implicit self esteem is a buffer function of self esteem against threatening relative to people with 
high implicit self esteem. Low implicit self esteem has negative consequences. Self related threat lead to decrease explicit self esteem. They also lead to lower explicit self esteem (Jones, Pelham, Mirenberg and Hett 2002). People with low implicit self esteem shows diminish level of aspiration after failure (Greenwald and Farnham, 2000) and more anxiety during very personal interview than high implicit self esteem individual (Spalding and Hordin 1999). Hett and Pelham (2001) suggested that high implicit self esteem may be more important for coping with stigmatization than high explicit self esteem. Blain and Crocker (1993), Taylor and Brown (1988) emphasize the well establish relationship between self esteem and self serving biases. People high in explicit self esteem are more likely to exhibit in group bias than are those low in self esteem (Crocker, Thompson, Mc Graw \& Ingerman, 1987).

Explicit self esteem and implicit self esteem might serve similar functions. Self affirmation theory proposed that positive self regard helps inoculate people against the stresses, strains and defeats of daily life (Taylor and Brown 1998). Positive implicit self regard might thus serve as a kind of shield against such threats to the self. Given the evidence that chronically accessible self schemata help people reject self inconsistent information and make sense of ambiguous information, implicit self regard might serve as a kind of automatically deployed, strategic self threat defense initiative. Positive implicit self regard might serve to discourage threats to the self before they become the, fixation of the conscious self and thus undermine self evaluation and self integrity

\section{CONCLUSION}

Self esteem is an important construct that is often related to academic achievement, social functioning and psychopathology in adolescents. In each society, people are characteristically ordered along a number of dimensions of stratification, social class, racial, religious, gender, age and ethnic. Occupations are arranged in a well recognized hierarchy of prestige (Hodge, Seigel and Rossi 1964). Ethnic preferences (Including racial) are surprisingly uniform across broad segment of the society and persist over long period of time (Bogardus, 1959). Since, such stratified social position commanded unequal social esteem. Social scientists have tended to take it for granted that those ranking lower in various status hierarchies would have lower self esteem than the more favored members of society.

Findings of the study indicate that student of general category posses high explicit self esteem and other backward category students having high implicit self esteem. In addition, implicit self esteem divided in name and surname provides individual and collective self esteem. Implicit self esteem as individualistic and collectively, other backward category shows higher than general and sc/st category. The results of present study emphasize on scheduled caste and schedule tribe category which have lowest self esteem on explicit and implicit self esteem. It can affect their academic achievements, social interaction and intergroup behavior. The university and college administrations have to understood this and encourage particular category by self esteem 
boosting program and remedial classes. It may be helpful to take in mainstream of society and healthy intergroup behavior.

\section{REFERENCES}

Bargh, J.A. \& Chartrand, T.L. (1999). The unbearable automati city of being. American Psychologist, 54, 462-479.

Bargh, J.A. (1984). Automatic and conscious processing of social information. In R.S. Wyer \& T.K. Srull (Eds.). Handbook of social cognition (Vol. 3, pp 1-44). Hillsdale, N.J.: Lawrence Erlbaum Associates.

Beggan, J.K. (1992). On the social nature of nonsocial perception: The mere ownership effect. Journal of personality and social psychology, 62, 229-237.

Belk, R.W. (1988). Possessions and the extended self. Journal of consumer research, 15, 139168.

Blain, B., \& Crocker, J. (1993). Self esteem and self serving biases in reaction to positive and negative events. An integrative review. In R.F. Baumeister (Ed.), Self esteem: The puzzle of low self regard (pp. 55-85), New York: Plenum.

Bogardus, E.S. (1959). “W.I. Thomas and Social origins”. Sociology and Social Research, 43, 365-69.

Bosson, J.K. \& Swann, W.B., Jr. (2009). Self esteem: Nature origins and consequences. In R. Hoyle \& M. Leary (Eds.), Handbook of individual differences in social behaviour (pp. 527-546). New York, NY: Guilford.

Bosson, J.K., Swann, W.B., Jr., \& Pennebaker, J.W. (2000). Stalking the perfect measure of implicit self esteem: The blind men and the elephant revisited? Journal of personality and social psychology, 79, 631-643.

Braddock, J.H., \& Mc Portland, J.M. (1987). How minorities continue to excluded from equal employment opportunities: Research on labour market and institutional barriers. Journal of social issue, 43, 5-39.

Cooper smith, S. (1982). The antecedents of self esteem. Palo Alto, CA: consulting Psychologists press.

Crocker, J., Thompson, L.L., McGraw, K.M. \& Ingerman, C. (1987). Downward comparison, prejudice and evaluations of others: Effect of self esteem and threat. Journal of personality and social psychology, 52, 907-916.

Croker, J. \& Major, B. (1989). Social stigma and self esteem: The self protective properties of stigma psychological review, 4, 608-630.

Cross, W.E. Jr. (1985) Black identity: Rediscovering the distinction between personal identity and reference group orientation. In M.B. Spencer, G.K. Brooking, \& W.R. Allen, (Eds.), Begining: The social and affective development of black children (pp. 155-171). Hillsdale, N.J.: Lawrence Erlbaum Associates.

Crossby, F., Bromely, S. \& Saxe, L. (1980). Recent obstrusive studies of Black and white discrimination and prejudice: A literature review. Psychological Bulletin, 87, 546-63. 
Devine, P.G. (1989). Stereotypes and prejudice: Their automatic and controlled components. Journal of Personality and Social Psychology, 56 (1), 5-18.

Dijksterhuis, A. \& Bargh, J.A. (2001). The person-behaviour express way: The automatic effect of social perception on behaviour. In M.P. Zanna (Ed.), Advances in experimental social psychology (Vol. 33, pp. 1-40). San Diego, CA: Academic Press.

Fazio, R.H. (1990). Multiple processes by which attitude guide behavior. The MODE model as an integrative framework. Advances in Experimental Social Psychology, 23, 75-109.

Feys, J. (1991). Briefly induced belongingness to self and preference. European journal of social psychology, 21, 547-552.

Fiske, S.T., Kitayama, S., Markus, H.R. \& Nishbett, R.E. (1998). The cultural matrix of social psychology. In D.T. Gilbert, S.T. Fiske, \& G. Lindey (Eds.). The handbook of social psychology (4 ${ }^{\text {th }}$ ed., Vol. 2. pp. 915-981). New York: McGraw-Hill.

Greenwald, A.G. \& Banaji. M.R. (1995). Implicit social cognition: Attitude, self esteem and stereotypes. Psychological review, 102, 4-27.

Greenwald, A.G. and Farnham, S.D. (2000). Using the Implicit Association test to measure self esteem and self concept. Journal of personality and social psychology, 79, 1022-1038.

Hetts, J.J., Sakuma, M. \& Pelham, B.W. (1990). Two roads to positive regard: Implicit and explicit self evaluation and culture. Journal of experimental social psychology, 35, 512559.

Hodge, Robert W., Paul M. Seigel, and Peter H. Rossi (1964). “Occupational prestige in the U.S.” American Journal of Sociology, 70: 286-302.

Hoorens, V., \& Nuttin, J.M. (1993). Over evaluation of own attributes. More ownership or subjective frequency? Social cognition, 11, 117-200.

Kahneman, D., Knetsch, J.L., \& Thaler, R.H. (1990). Experimental test of the endowment effect and the coase theorem. Journal of political economy, 98, 1325-1347.

Kitayama, S., \& Karasawa, M. (1997). Implicit self esteem in Japan: Name letters and birthday numbers. Personality and social psychological Bulletin, 23, 736-742.

Markus, H.R. \& Kitayama, S. (1991). Culture and self: Implications for cognition, emotion, and motivation. Psychological review, 98, 224-253

Mayo Clinic (2009). Self esteem check: Too low, too higher or just right? Retrieved February 1, 2009, from http://www.mayoclinic.com/health/self teem/MH00128.

Nuttin, J.M.Jr. (1985). Narcissism beyond Gestalt and awareness: The name letter effect. European. Journal of social psychology, 15, 353-361.

Pelhum, B.W. \& Hetts, J.J. (1999b). Implicit and explicit personal and social identity: Toward a more complete understanding of the social self. In T.R. Tyler, R.M. Kramer, \& O.P. John (Eds.). The psychology of the social self. Mahwah, N.J.: Lawrence Erlbaum Associates.

Porter, J.R. \& Washington, R.E. (1993). Minority identity and self esteem. Annual review of sociology, 19, 139-161.

Porter, J.R., \& Washington, R.E. (1979). Black identity and self esteem. A review of studies of black self concept, 1968-1978. Annual review of sociology, 5, 53-74. 
Porter, J.R., \&Washington, R.E. (1989). Development in research on Black identity and self esteem: 1979-1988.Revue international de Psychologie Sociale, 2, 339-353.

Rosenberg, M. (1979). Conceiving the self. New York: Basic Books.

Ruggiero, K.M. \& Taylor, D.M. (1995). Coping with discrimination. How disadvantaged group members percieve the discrimination that confront them. Journal of personality and social psychology, 68, 826-838.

Sidanius, J. and Pratto, F. (1999) Social Dominance: An intergroup theory of social hierarchy and oppression. Cambridge: Cambridge University Press.

Spalding, L.R., \& Hardin, C.D. (1999). Unconscious unease and self handicapping: Behavioural consequences of individual differences in implicit and explicit self esteem. Psychological science, 10, 535-539.

Stephan, W.G., \& Rosenfield, D. (1978). Effects of desegregation on racial attitudes. Journal of personality and social psychology, 36, 795-804.

Tajfel, H. (1970). Experiments in intergroup discrimination. Scientific American, 223, 96-102.

Taylor, D.M., Wright, S.C. \& Porter, L.E. (1994). Dimensions of perceived discrimination: The personal group discrimination discrepancy. In M.P. Zanna \& J.M. Olson (Eds.), The psychology of prejudice: The Ontario symposium (Vol. 7, pp. 233-256). Hillsdale, N.J. : Lawrence Erlbaum Associates.

Taylor, D.M., Wright, S.C., Moghaddam, F.M., \& Lalonde, R.N. (1990). The personal/group discrimination discrepancy: Perceiving my group, but not myself to be a target for discrimination. Personality and social psychology Bulletin, 16, 253-262.

Triandis, H.C. (1989). The self and social behavior in differing cultural contexts. Psychological review, 96, 506-520.

Triandis, H.C. (1995). Individualism \& Collectivism. Boulder Co: West vew.

How to cite this article: S Tiwari, A Patel, D Kumar (2016), Assessment of Explicit and Implicit Self Esteem among Students of Different Social Categories, International Journal of Indian Psychology, Volume 3, Issue 3, No. 6, DIP: 18.01.113/20160303 